\title{
Remote sensing of spectral aerosol properties: A classroom experience
}

\author{
Robert C. Levy ${ }^{1,2,3}$, Rachel T. Pinker ${ }^{3}$ \\ ${ }^{1}$ Science Systems and Applications Inc., Lanham MD \\ ${ }^{2}$ Laboratory for Atmospheres, NASA/Goddard Space Flight Center, Greenbelt MD \\ ${ }^{3}$ Department of Atmospheric and Oceanic Science, University of Maryland, College Park, MD
}

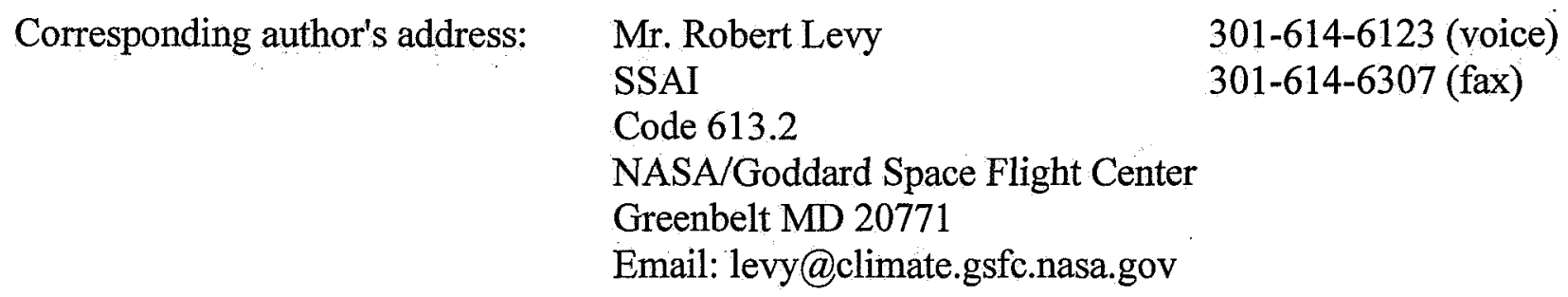

Revised for publication, Section "Education", BAMS

July 2006 


\title{
Capsule
}

This paper describes a graduate level class project designed to develop understanding of aerosol optical properties and methods for their retrieval from satellite observations.

\begin{abstract}
Bridging the gap between current research and the classroom is a major challenge to today's instructor, especially in the sciences where progress happens quickly. NASA Goddard Space Flight Center and the University of Maryland teamed up in designing a graduate class project intended to provide a hands-on introduction to the physical basis for the retrieval of aerosol properties from state-ofthe-art MODIS observations. Students learned to recognize spectral signatures of atmospheric aerosols and to perform spectral inversions. They became acquainted with the operational MODIS aerosol retrieval algorithm over oceans, and methods for its evaluation, including comparisons with groundbased AERONET sun-photometer data.
\end{abstract}




\section{Introduction}

The direct and indirect radiative effects of aerosols on climate and climate change remain a source of uncertainty in climate research (IPCC, 2001). Aerosols (also known as particulate matter (PM)) play important roles in precipitation processes, reduced visibility, and human morbidity (Samet et al., 2000). Before the satellite era, information on aerosols came from limited surface based observations, which are not sufficient to describe their spatial and temporal variability of aerosols.

With their vantage high above the earth, satellite observations of reflected and emitted radiances are increasingly being used to monitor aerosols and their interactions within the climate system (King and Kaufman, 2000). A highly successful project is the NASA's Moderate Imaging Spectrometer (MODIS) (Salomonson et al., 1989), which has been observing from aboard the Terra (since 2000) and Aqua (since 2002) satellite platforms. By observing spectral radiances in 36 channels (from 0.412 to $14.2 \mu \mathrm{m}-\mathrm{http}: / /$ modis.gsfc.nasa.gov) and at resolution ranging from $250 \mathrm{~m}$ to $1 \mathrm{~km}$, MODIS is highly suitable for deriving aerosol properties over the oceans (Tanré et al., 1996; Tanré et al., 1997). The MODIS polar geo-synchronous orbit is such that most of the globe is covered each day, and completely covered every two days, thus providing comprehensive observations. Since the MODIS data are well characterized and easy to access, they are suitable for introducing students to the physics of remote sensing.

As part of a graduate course in Remote Sensing, students used MODIS data and focused on the following:

- Understanding how aerosols interact with reflected solar radiation. 
- Obtaining working knowledge of inversion techniques for retrieving aerosol properties over oceans.

- Implementing the MODIS algorithm to retrieve aerosol properties from observations.

- Contrasting aerosol properties from different sites, and to relate them to geography and season.

- Evaluating satellite retrievals in the context of ground based aerosol measurements.

This paper reviews the basic physics of remote sensing of aerosols and describes selected findings and lessons learned by the students. Data, codes, and detailed instructions needed to perform the exercises are available at:

http://www.atmos.umd.edu/ levy/MODIS_Aerosol_Project

\section{Remote sensing of aerosols over the ocean from MODIS and AERONET}

Aerosols are suspended liquids or solids in the atmosphere, ranging in size from a few molecules to tens of micrometers. Aerosols having radii of between about $0.1 \mu \mathrm{m}$ and $20 \mu \mathrm{m}$ are of primary interest, where $1.0 \mu \mathrm{m}$ denotes separation between "fine" and "coarse" Modes. The aerosol optical depth (AOD or $\tau$ ) defines the integral of the light extinction by aerosols within an atmospheric column. Spectral dependence of $\tau$ is related to the aerosol size distribution (Eck et al, 1999), and the Fine Mode Weighting (FMW or $\eta$ ) describes the contribution of the fine aerosols to the total $\tau$ at a specific wavelength ( $\lambda$ ). By convention, $\tau$ and $\eta$ are reported for $\lambda=0.55 \mu \mathrm{m}$.

Sun photometers have been in operation for many years and when calibrated properly, provide accurate measurements of spectral $\tau$ (function of $\lambda$, i.e. $\tau_{\lambda}$ ). By accounting for known effects of molecular scattering (Rayleigh scattering) and gas absorption, sun-photometer measurements of spectral 
direct beam extinction are directly related to $\tau_{\lambda}$ as expressed by the Beer-Bouger extinction law. The current standard for ground-based sunphotometry is the AERosol Robotic NETwork (AERONET) (Holben et al., 1998), providing continuous daytime measurements of $\tau_{\lambda}$ with accuracy of \pm 0.01 at most wavelengths (Remer et al., 2005; Pinker et al., 2001; Eck et al., 2003) at over a hundred sites globally. Through measurements of spectral diffuse sky radiation, AERONET also provides estimates of aerosol size distribution (Dubovik and King, 2000).

Whitby (1978) showed that a series of log-normal size distributions accurately describe aerosol sizes. In most situations, aerosols that interact with solar radiation can be modeled as a weighted combination of two log-normal modes, one for the fine and one for the coarse (Wang and Gordon, 1994) Theoretically, using radiative transfer codes, one can pre-compute a look-up table (LUT) of simulated satellite-observed reflectance (normalized radiance), arising from a variety of aerosol conditions for a subset of realistic geometries (satellite and sun angles) and total aerosol loadings $\tau$ (Tanré et al., 1997). For MODIS, there are four choices of fine modes and five choices of coarse modes, simulated for 2304 solar/satellite angle combinations and seven values of $\tau$ indexed by $0.55 \mu \mathrm{m}$ (Levy et al., 2003; Remer et al., 2005). Note that the actual spectral reflectance for each mode includes contributions from the surface and the molecular atmosphere (Rayleigh scattering).

MODIS over-ocean aerosol properties (known as 'Level 2' products) are retrieved at $10 \mathrm{~km} \mathrm{x} 10$ $\mathrm{km}$ resolution, meaning that the spectral reflectance values used for the retrieval must be representative of the target area. Remer et al., (2005) describes how the high resolution (250 and $500 \mathrm{~m}$ resolution) MODIS spectral reflectance observations (known as 'Level 1' data) are aggregated, corrected for gas absorption, and selectively averaged (including glint, cloud, and sediment masking), in order to represent the $10 \mathrm{~km}$ box. The aerosol retrieval assumes that this 'Level 2' spectral reflectance arises from the radiative effects of a combination of fine and coarse modes within the atmospheric column. 
The total $\tau$ is set to fit the observed reflectance at one wavelength, and $\eta$ is calculated to match the spectral dependence of $\tau_{\lambda}$. Incorrect values of $\eta$ lead to larger spectral 'fitting errors'. A separate solution is found for each of the twenty combinations of fine and coarse modes, so that the 'best' solution is the one combination of fine (' $\mathrm{f}$ ) and coarse (' $\mathrm{c}$ ') modes with the least fitting error. The spectral AOD $\left(\tau_{\lambda}\right)$ and $\eta$ are results of the inversion.

Ichoku et al. (2002) developed an algorithm to operationally compare MODIS (Level 2) and AERONET products, by addressing the issue of spatial and temporal matching. Remer et al. (2002, 2005 ) used this approach in 'validation' of MODIS total $\tau$ retrievals over the ocean on a global scale. Remer et al., (2005) also discussed retrievals of $\tau_{\lambda}$ and how they relate to retrievals of aerosol size parameters. In our class project, we used a set of nine MODIS/AERONET co-locations in order to understand how the MODIS inversion works, as well as to study the difference between MODIS and AERONET retrievals of $\tau_{\lambda}$.

\section{The class project}

The aerosol inversion, as summarized in a few paragraphs above, is actually quite complicated. It was assumed that students could best understand inversion and the resulting products by performing a simplified inversion "by hand." Students used MODIS (Level 2) spectral reflectance as observed over the ocean near coastal and island AERONET sites (Figure 1) during 2001 and 2002. Coincident AERONET-derived $\tau_{\lambda}$ data were used to evaluate the MODIS-derived products. In all, nine pairs of collocated MODIS/AERONET data were used for the project (Table 1).

The skills required for this project are familiarity with FORTRAN compiling and use of "Y versus X" plotting software. A Fortran source code and data files with instructions for downloading, compiling and running the programs, are provided to the students and are now publicly available (at 
http://www.atmos.umd.edu/ levy/MODIS_Aerosol_Project). The input data sets were formatted for easy import into a spreadsheet program (such as MS-Excel).

\section{Results}

\subsection{Aerosols and Spectral Radiances}

The students were given Terra-MODIS (Level 2) spectral reflectances at 7 channels for each of eight co-locations (first eight columns in Table 1). Figure 2 presents plots of reflectance versus wavelength (spectral reflectance) for the eight MODIS observations. All locations show decreasing reflectance with wavelength, primarily attributed to lower oceanic reflectance and molecular (Rayleigh) scattering at longer wavelengths.

They found that different spectral dependence was related to location. Both Ascension Island and Capo_Verde have "flatter" spectral dependence than the other sites. Both sites are in the Atlantic Ocean and both (especially Capo Verde) are often in the path of the African dust aerosol (Carlson and Caverly, 1977; Grousse et al., 1988; Prospero, 2001). Dust aerosols show lower spectral dependence than other types of aerosols (Eck et al., 1999) because of the larger number of coarse aerosols that scatter in the longer wavelengths. Venise and COVE are urbanized areas, and are characterized by urban/industrial aerosols (Remer et al., 1998; Dubovik et al., 2002). Due to the larger fraction of the fine mode in urban aerosols, these sites display larger spectral dependence (Eck et al., 1999).

\subsection{Hand-Calculated Aerosol Optical Depth}

This exercise was designed to introduce students to the MODIS aerosol retrieval algorithm, by having them manually perform a MODIS-like inversion. A simplified look-up table was provided for a pair of fine and coarse modes at selected geometries (from the www). Also provided was the MODIS 
spectral reflectance for Gotland (ninth column in Table 1). The students performed the following tasks, (analogous to those within the operational algorithm).

To start, they interpolated the entire LUT to the specific solar/surface/satellite geometry measured by MODIS (Figure 3). This specific-angle LUT was used to fit the observed spectral reflectance. This fitting was done by 'halving' iteration on $\eta$, coincidently with interpolation on indexed total $\tau$ within the LUT. For the first iteration, they attempted to match the satellite reflectance by assuming that the aerosol was of coarse mode only (i.e. $\eta=0.0)$. This resulted in total $\tau$ at $(0.55 \mu \mathrm{m})$ of about 0.19 , with large differences ('fitting error') between calculated and observed spectral reflectance (Figure 4). Assuming only fine mode aerosol $(\eta=1.0)$ led to lower fitting errors. Trying half and half $(\eta=0.5)$ showed significant improvement, while 'halving' again $(\eta=0.75)$ resulted in an even better match with observations. Following Tanré et al. (1996), the iteration was considered complete after ten iterations and when the simulated reflectance was within $3 \%$ of the observations (Figure 5). In the case at hand, convergence was achieved after three to four iterations. The accepted solution was estimated to be $\eta=0.79$ and $\tau=0.22$ (at $0.55 \mu \mathrm{m}$ ), with fitting error $\varepsilon$ of about $2.5 \%$, but depended on how the students chose to handle significant digits in their calculations.

\subsection{Global aerosol retrievals and comparison with sun photometer data}

How do aerosol properties vary globally? The students were given instructions for compiling and running a stand-alone version of the operational MODIS algorithm (also available from the listed www). Using MODIS angle and reflectance data described in section 4.1 as input, the aerosol optical properties were retrieved for each case. Figure 6 compares the spectral dependence of $\tau_{\lambda}$, retrieved from both MODIS and AERONET at eight sites. 
The spectral dependence of $\tau$ was seen to resemble the observed spectral dependence of the reflectance for each location. This reflects the characteristics of the aerosols near each site. As expected, the spectral dependence of $\tau_{\lambda}$ is smaller (flatter) for dusty or mid-ocean sites (Ascension Island, Capo Verde), than for more polluted (urban/industrial or smoke aerosol) near.coastlines (COVE, Venice). Africa shows a combination of small (presumably smoke) and larger sea salt aerosols. The retrieval of $\eta$ mirrors the spectral dependence of $\tau_{\lambda}$, with the larger particles over Ascension Island and Capo Verde, and the smaller particles over COVE and Venise. These results are consistent with what is known about aerosol characteristics in these regions.

Figure 6 shows good visual agreements for Venise \#1, Villefranche and COVE. These three sites are from regions known to be dominated by fine mode, aerosols and the spherical aerosol assumption (Mie theory) is appropriate. On the other hand, for regions dominated by larger nonspherical dust particles, the differences between the two products are considerable (e.g., at Ascension Island and Dahkla). This implies that the aerosol models employed in the MODIS algorithm are not sufficient for describing the ambient aerosol properties at these sites (e.g. Levy et al., 2003). Interestingly, the differences between the MODIS and AERONET retrievals for regions with large aerosols tend to increase with increasing wavelength, while those for the regions with small aerosols tend to increase with decreasing wavelength.

\section{Summary and Conclusions}

The objective of this project was to expose graduate students to current research in aerosol remote sensing. The students learned about the spectral dependence of aerosol scattering and how it is exploited in the MODIS aerosol retrieval algorithm to estimate aerosol optical properties. 
Due to the importance of aerosols on atmospheric radiative processes and their climatic implications, the project is relevant to interdisciplinary problems. Moreover, MODIS represents the state of the art science and technology for remote sensing of several earth-atmosphere processes. MODIS (as well as other satellite) data are free, easily available, and increasingly useful in many applications, so there is a great need to learn how to process such data and interpret them in new and exciting ways. Projects such as this one provide opportunity for students and young scientists to become familiar with (and less apprehensive of) datasets of this magnitude.

Acknowledgements: At the time of project development, Robert Levy was a student in Rachel Pinker's Remote Sensing class (METO624) in the Department of Atmospheric and Oceanic Science, University of Maryland. Five other students performed the tasks of this project (Hiroko Kato, MyeongJae Jeong, Ruiming Chen, Fan Lei and Hengmao Wang). Their figures have been re-created here for consistency. We thank Yoram Kaufman and Lorraine Remer for the idea of creating this project. 


\section{References:}

Carlson, T. and R. Caverly, 1977: Radiative characteristics of Saharan dust at solar wavelengths. Transactions-American Geophysical Union, 58 (6): 555-555.

Dubovik, O. and M. D. King, 2000: A flexible inversion algorithm for retrieval of aerosol optical properties from Sun and sky radiance measurements. J. Geophys. Res.-Atmos., 105, D16, 20673-20696.

Dubovik, O., B. Holben, T. F. Eck, A. Smirnov, Y. J. Kaufman, M. D. King, D. Tanré and I. Slutsker, 2002: Variability of absorption and optical properties of key aerosol types observed in worldwide locations. J. Atmos. Sci., 59, 3, 590-608.

Eck, T. F., B. N Holben, J. S. Reid, O. Dubovik, A. Smirnov, N. T. O’Neill, I. Slutsker and S. Kinne, 1999: Wavelength dependence of the optical depth of biomass burning, urban and desert dust aerosols, J. Geophys. Res.-Atmos., 104, D8, 31,333-31,349.

Eck, T. F., and Coauthors, 2003: Variability of biomass burning aerosol optical characteristics in southern Africa during the SAFARI 2000 dry season campaign and a comparison of single scattering albedo estimates from radiometric measurements. J. Geophys. Res., 108(D13), 8477, doi:10.1029/2002JD002321.

Intergovernmental Panel on Climate Change, 2001: Climate Change 2001: the scientific basis, Cambridge Univ. Press, New York,. 
Grousse, F. E., B. Hamelin, P. E. Biscaye, J. Prospero, 1988: Trans-Atlantic transport of aerosols-evidence from anthropogenic PB isotope signatures. Chemical Geology, 70 (1-2): 196-196.

Holben, B. N., and Coauthors, 2001: An emerging ground-based aerosol climatology: Aerosol Optical Depth from AERONET. J. Geophys. Res., Vol. 106, No. D11, 12,067-12,097.

Ichoku, C., D. A. Chu, S. Mattoo, Y. J. Kaufman, L. A. Remer, D. Tanre, I. Slutsker, and B. N. Holben, 2002: A spatio-temporal approach for global validation and analysis of MODIS aerosol products. Geophys. Res. Lett., 29, doi: 10.1029/2001GL013206.

Kaufman, Y. J., D. Tanré, and O. Boucher, 2002: A satellite view of aerosols in the climate system. Nature, Vol. 419, 215-223.

Levy, R. C., L. A. Remer, D. Tanré, Y. J. Kaufman, C. Ichoku, B. N. Holben, J. M. Livingston, P. B. Russell and H. Maring, 2003: Evaluation of the MODIS retrievals of dust aerosol over the ocean during PRIDE. J. Geophys. Res., 108 (D14), 10.1029/2002JD002460

Pinker, R. T., G. Pandithurai, B. N. Holben, O. Dubovik, and T. O. Aro, 2001: A dust outbreak episode in sub-Sahel West Africa, J.Geophys.Res., 106, D19, 22923 - 22930.

Prospero J. M, 2001: African dust in America. EOTIMES 46 (11): $24-27$. 
Remer, L. A., and Coauthors, 2002: Validation of MODIS aerosol retrieval over ocean. Geophys. Res. Lett., 29, 10.1029/2001GL013204.

Remer, L.A. and Coauthors, 2005: The MODIS aerosol algorithm, products and validation. J. Atmos. Sci., 62, 947-973.

Tanré ‘, D., M. Herman, and Y. J. Kaufman, 1996: Information on aerosol size distribution contained in solar reflected spectral radiances. J. Geophys. Res., 101 (D14), 19 043-19060.

Tanré `, D., Y. J. Kaufman, M. Herman, and S. Mattoo, 1997: Remote sensing of aerosol properties over oceans using the MODIS/EOS spectral radiances. J. Geophys. Res., 102 (D14), 16 971-16 988.

Wang M. and H. R. Gordon, 1994: Radiance reflected from the ocean-atmosphere system: Synthesis from individual components of the aerosols size distribution, Applied Optics, 33, 7088-7095.

Whitby, K. Y, 1978: The physical characteristics of sulfur aerosols, Atmos. Environ., 12, 135159. 


\section{List of Tables}

Table 1. MODIS/AERONET co-locations used for this project. The first eight (normal font) are used in the MODIS/AERONET comparisons. The ninth site (in italic) was used for the manual inversion. 


\section{List of Figures}

Figure 1. Map of AERONET sites selected for this study.

Figure 2. Plot of reflectance vs. wavelength (spectral reflectance) for eight MODIS observations. Data used for the later "manual" retrieval (Gotland) are plotted with squares.

Figure 3. LUT table interpolated to MODIS observed Geometry. Filled circles are the modeled reflectance from the small mode for each of five indexed optical depths $(0.2,0.5,1.0,2.0$ and 3.0 at $0.55 \mu \mathrm{m}$ ), while the open squares are the modeled reflectance arising from the coarse mode. The filled triangle (dashed line) is the modeled Rayleigh reflectance, and the filled square (dotted line) are the MODIS observations for Gotland. Reflectance from each mode increases monotonically with $\tau$ (AOD).

Figure 4. Reflectance calculated "by hand" (colored circles) versus the reflectance observed by MODIS (black squares). Different colors represent different choices of the small mode weighting, $\eta$. The best fit to MODIS data (black squares) arises from $\eta=0.787$ (orange).

Figure 5. Fitting error (green), fine mode weighting (red) and aerosol optical depth (blue) calculated at each iteration of the MODIS retrieval.

Figure 6. Spectral $\tau_{\lambda}$ retrieved by MODIS (solid) and AERONET (dashed) for each location. MODIS retrieved $\eta$ and fitting error are indicated on each plot. 
Table 1.

\begin{tabular}{|c|c|c|c|c|c|c|c|c|c|}
\hline Date & $4 / 11 / 2001$ & $8 / 15 / 2002$ & $8 / 2 / 2001$ & $8 / 19 / 2002$ & $7 / 11 / 2002$ & $3 / 23 / 2001$ & $9 / 13 / 2002$ & $8 / 17 / 2001$ & $1 / 1 / 02$ \\
\hline DOY & 102 & 227 & 215 & 231 & 192 & 83 & 256 & 230 & 190 \\
\hline Time (UTC) & $15: 45$ & $11: 55$ & $11: 10$ & $11: 15$ & $9: 30$ & $11: 45$ & $11: 15$ & $15: 25$ & $11: 20$ \\
\hline Location & Arica & $\begin{array}{l}\text { Ascension_ } \\
\text { Island }\end{array}$ & Venise \#1 & Villefranche & Venise \#2 & Capo_Verde & Dahkla & COVE & Gotland \\
\hline
\end{tabular}




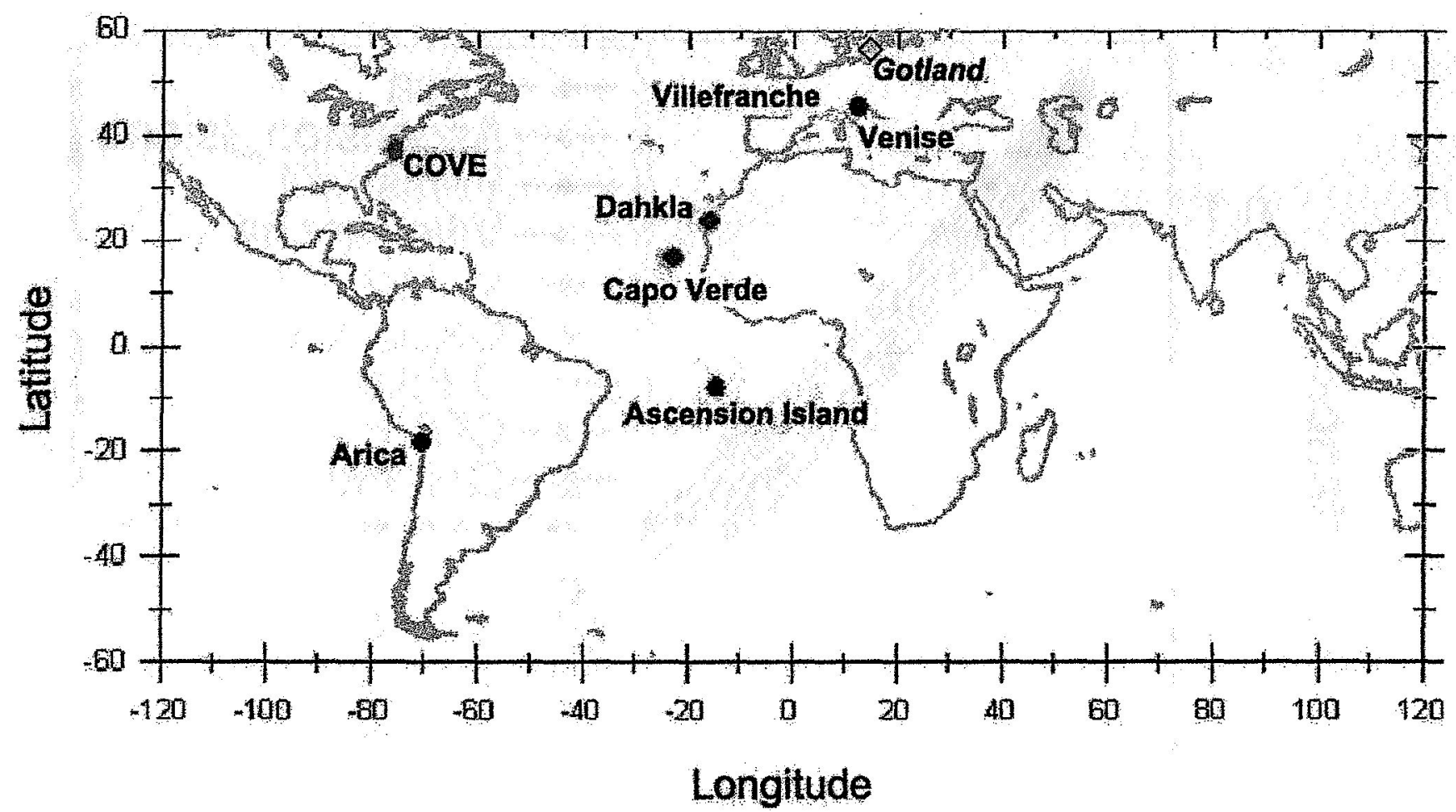

Figure 1. Map of AERONET sites selected for this study. 


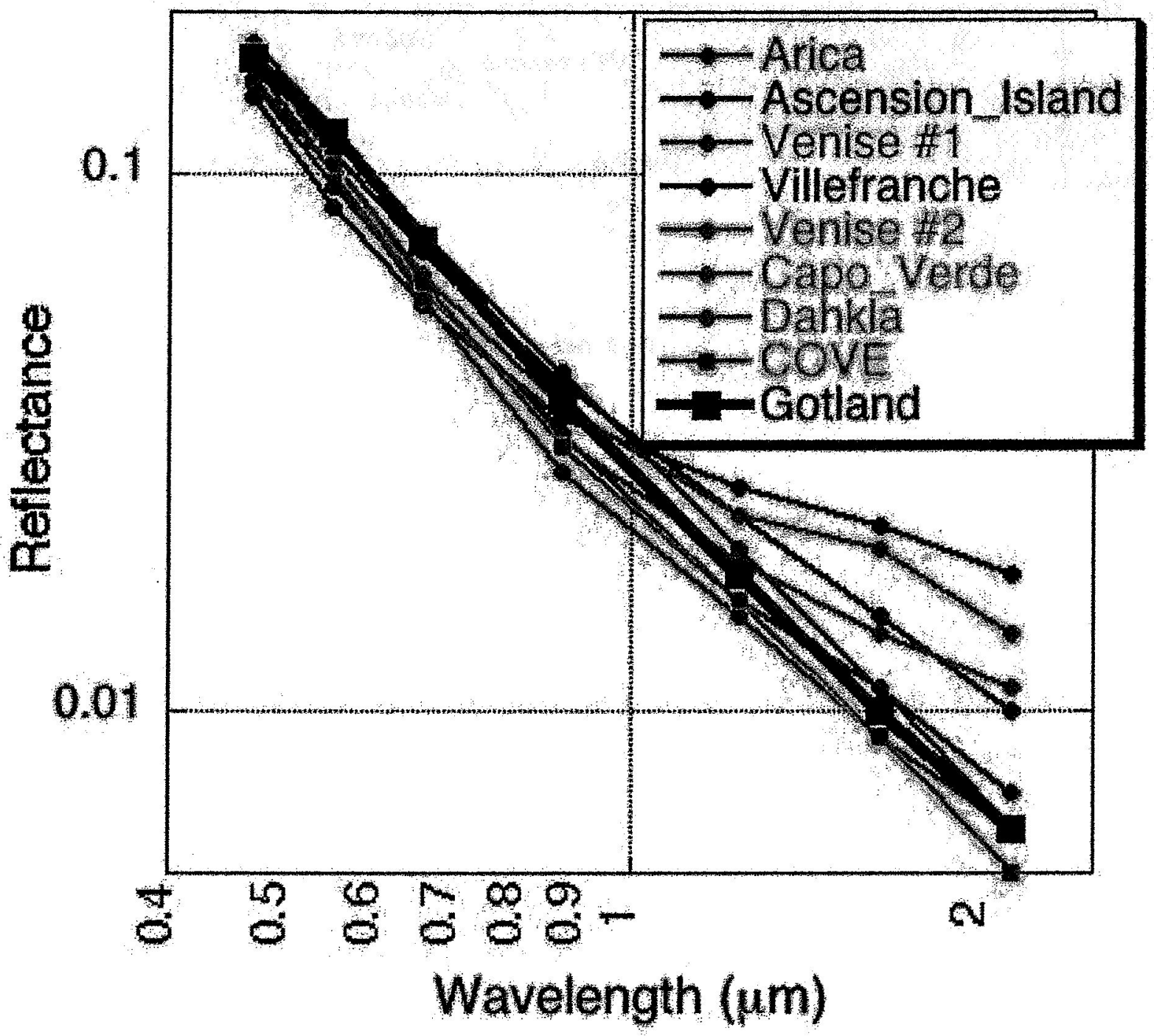

Figure 2. Plot of reflectance vs. wavelength (spectral reflectance) for eight MODIS observations. Data used for the later "manual" retrieval (Gotland) are plotted with squares. 


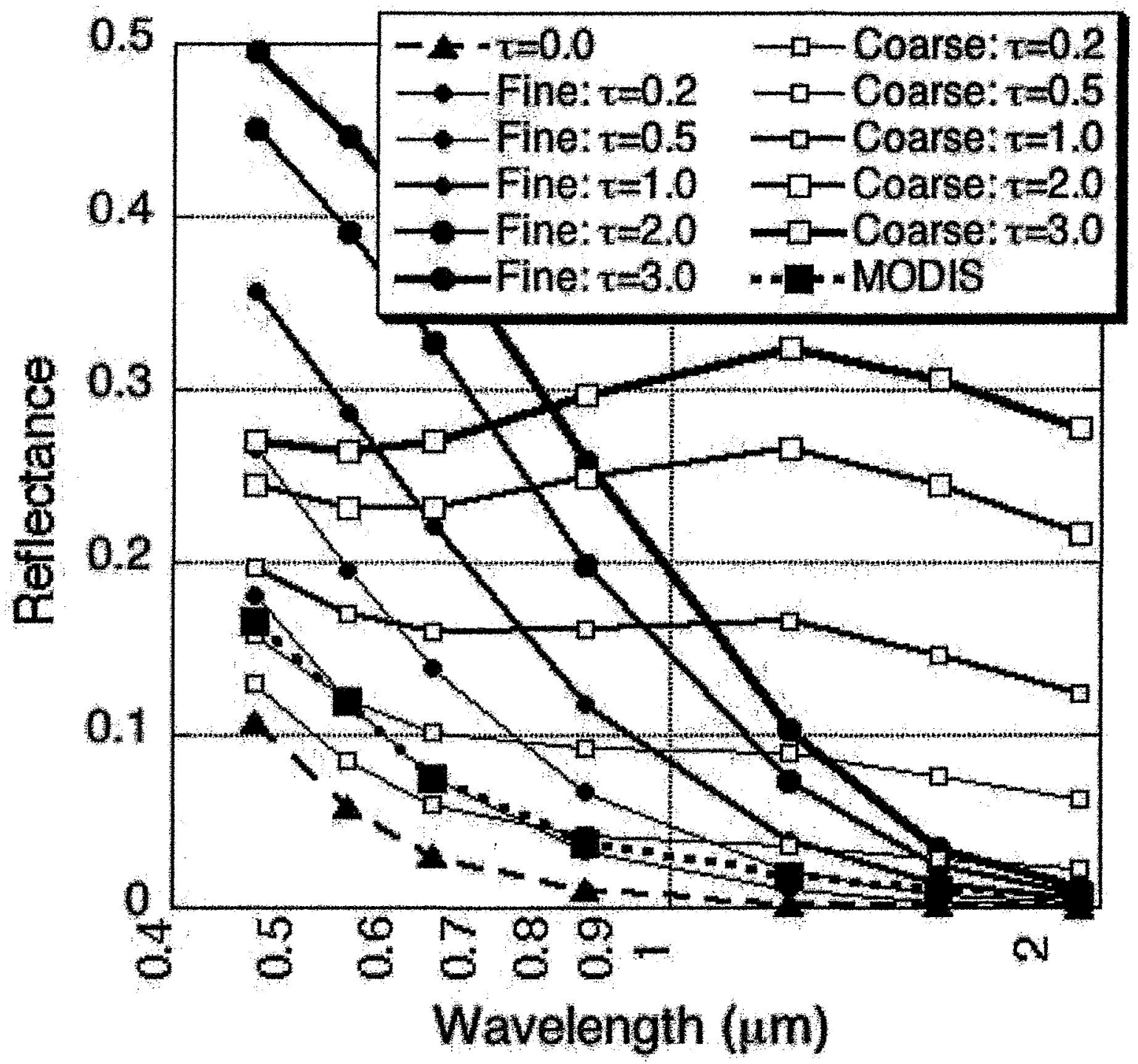

Figure 3. LUT table interpolated to MODIS observed Geometry. Filled circles are the modeled reflectance from the small mode for each of five indexed optical depths $(0.2,0.5,1.0,2.0$ and 3.0 at $0.55 \mu \mathrm{m}$ ), while the open squares are the modeled reflectance arising from the coarse mode. The filled triangle (dashed line) is the modeled Rayleigh reflectance, and the filled square (dotted line) are the MODIS observations for Gotland. Reflectance from each mode increases monotonically with.t(AOD). 


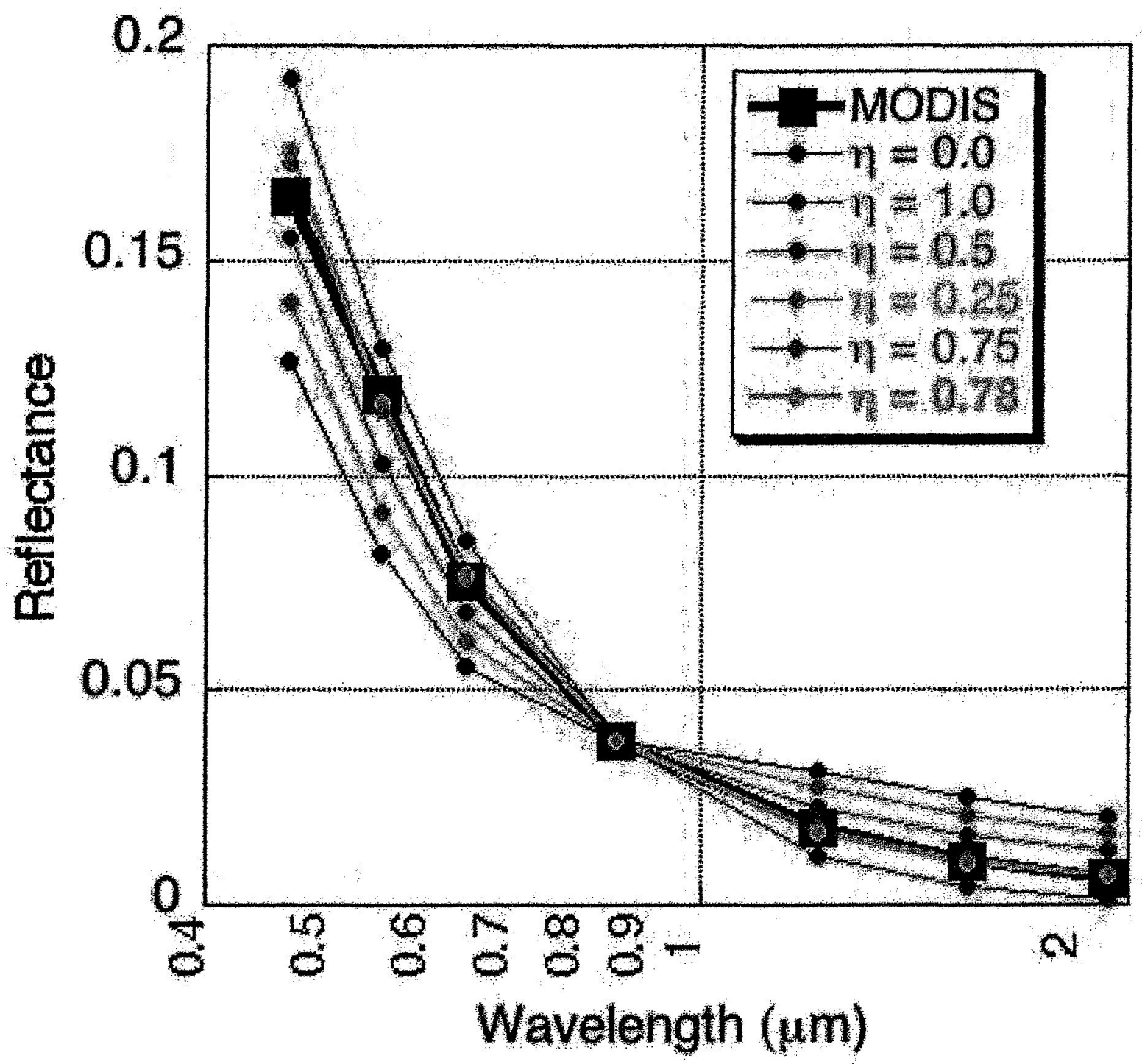

Figure 4. Reflectance calculated "by hand" (colored circles) versus the reflectance observed by MODIS (black squares). Different colors represent different choices of the small mode weighting, $\eta$. The best fit to MODIS data (black squares) arises from $\eta=0.787$ (orange). 


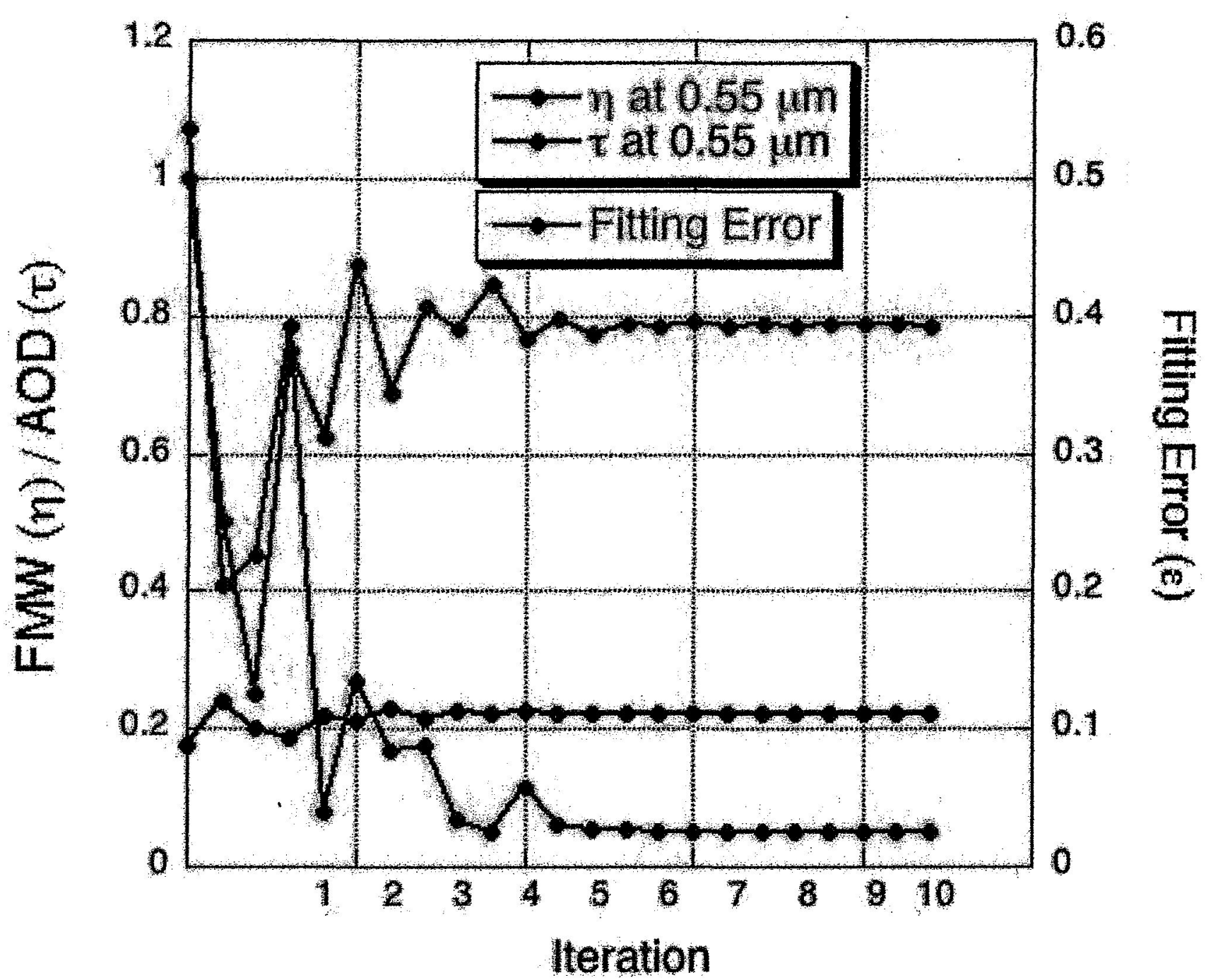

Figure 5. Fitting error (green), fine mode weighting (red) and total AOD (blue) calculated in each iteration of the MODIS retrieval. 

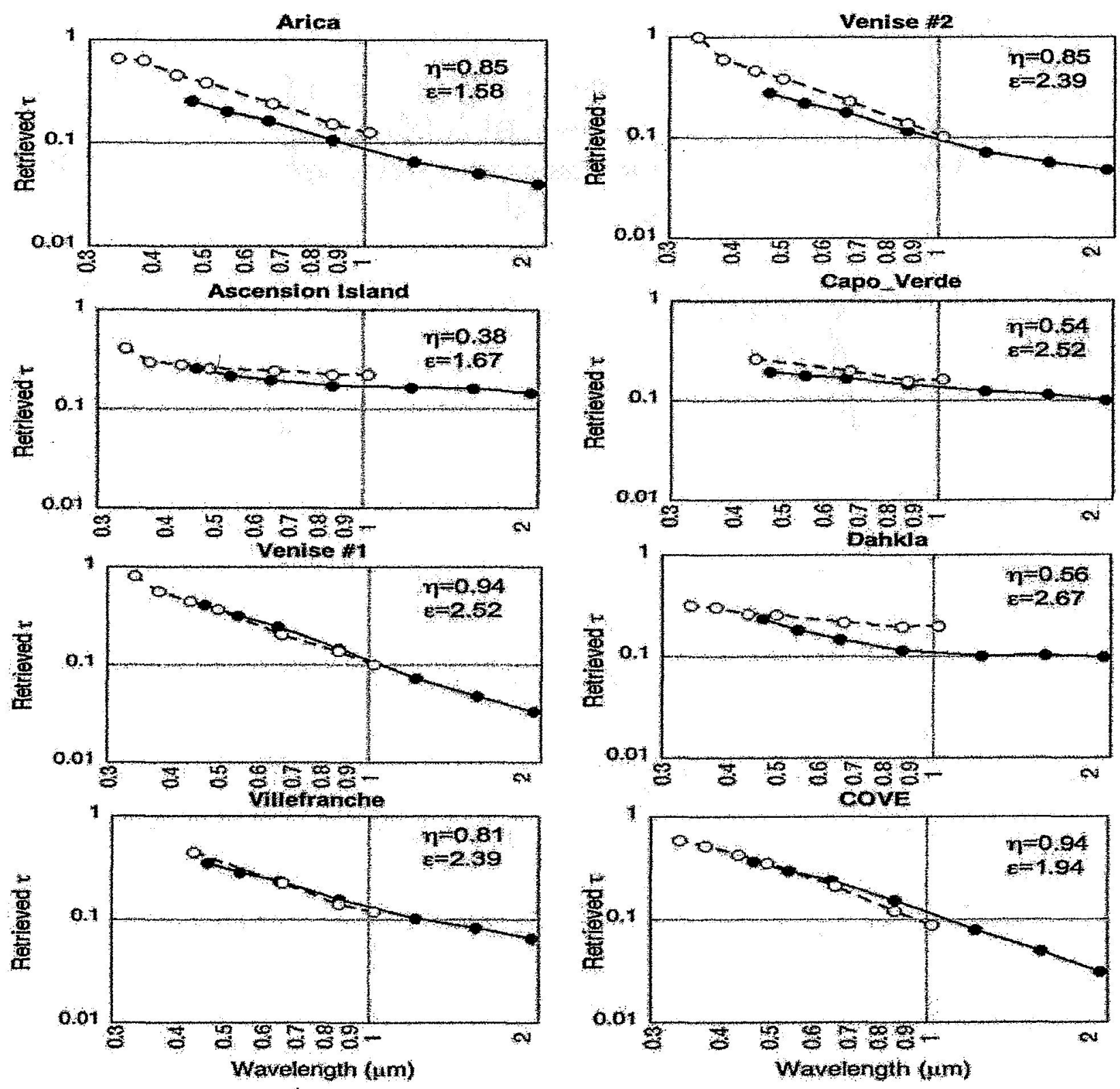

Figure 6. Spectral $\tau_{\lambda}$ retrieved from MODIS (solid) and AERONET (dashed) for each location. MODIS retrieved $\eta$ and fitting error $(\varepsilon)$ are indicated for each retrieval. 